\title{
The importance of Torg ratio in patients with ankylosing spondylitis
}

\author{
Sinan Bakirci', Safinaz Ataoglu², Tugce Pasin ${ }^{2}$, Handan Ankarali ${ }^{3}$ \\ 'Usak University, School of Medicine, Department of Anatomy, Usak, Turkey \\ ${ }^{2}$ Duzce University, School of Medicine, Department of Physical Therapy and Rehabilitation, Duzce, Turkey \\ ${ }^{3}$ Medeniyet University, School of Medicine, Department of Biostatistics, Istanbul, Turkey \\ Copyright @ 2018 by authors and Annals of Medical Resarch Publishing Inc.
}

\begin{abstract}
Aim: Ankylosing spondylitis is a disease of unknown etiology. It is an inflammatory, rheumatic disease basically influencing peripheral articulations and extra-articular structures. It is chronic and it leads to deformities in vertebra. Deformities in vertebras may lead to cervical spinal stenosis in long term that may result in cervical myelopathy which is a serious health disorder. One of the methods to evaluate the diameter of cervical canal is Torg ratio.

Materail and Methods: In this study, patients with ankylosing spondylitis for more than 10 years have been examined through lateral cervical radiograms. The patients were both male and female whose ages range from 40-50 to 50-60. Morphometric measurements of cervical vertebras were made digitally and the differences between groups were revealed.

Results: Considering the percentages of the narrowest cervical spinal canal diameter (CSCD) from anterior to posterior, it was seen that females have the highest vertebra levels in C4 and C6 whereas males have the highest vertebra levels in C3 and C7. The difference between males and females was found statistically significant $(P=0.021)$. Minimum Torg ratio vertebra levels for females was in $\mathrm{C} 6$ for the age group 40-50 while it was $\mathrm{C} 7$ for the age group 50-60. As for the males, both age groups' Torg ratio vertebra levels was minimum in $\mathrm{C} 7$.

Conclusions: In this sense, it was concluded that patients with ankylosing spondylitis for more than 10 years should be monitored more carefully for neurological deficits that stem from cervical myelopathy.
\end{abstract}

Keywords: Ankylosing Spondylitis; Torg Ratio; Cervical Myelophaty; Spinal Canal.

\section{INTRODUCTION}

Spinal canal, also known as vertebral canal, is a structure formed by vertebral foramens covering spinal cord and meninges as well as veins that surround spinal cord. The canal is protected with posterior longitudinal ligament on the front and ligamentum flavum on the back. When spinal canal diameter is lower than $13 \mathrm{~mm}$ in cervical regions, congenital spinal canal stenosis should be taken into consideration. Transvers diameter of spinal cord passing through spinal canal increases after C3 segment and reaches maximum level in $\mathrm{C} 5$ segment. It narrows downwards gradually and reaches minimum level in T8 (13-10 mm C3-T1 respectively).Anteroposterior diameter of spinal cord (SCD) varies less. SCD decreases gradually from C3 segment to upper thoracic segments. SCD remains stable in the same sizes in distal thoracic segments (8-6 $\mathrm{mm}$ C3-T1 respectively) (7). Maximum values measured in cervical region regarding SCD varies between $10 \mathrm{~mm}$ to $12 \mathrm{~mm}$ and the highest levels belong to $\mathrm{C} 3$ segment (13). Measurements of cervical canal can be obtained from lateral radiographies, MRI and CT images as well as cadaveric study. The distance between film and tube and using different magnifications change the results in lateral radiographies $(7,8,13)$.

Torg ratio refers to the ratio of thickness between middle points on the anterior and posterior facet of vertebral body (VBD) to anterior-posterior diameter of cervical spinal canal in lateral radiographies. Using this ratio as an indicator of cervical myelopathy and neuropraxia is preferred because it reduces the errors in non-standard radiographs which stem from zooming. Even if Torg ratios differ based on sex and race, it roughly ranges from 0.87 to 1.12 (9). Torg ratio less than 0.80 is a high sensitivity at a rate of $93 \%$ in footballers who experience temporary neuropraxia [14] However, since Torg ratio has "low positive predictive value $(0.2$ per cent)", it is not proper to use it as screen test to detect the suitability of the sportsman for the sports 
branches such as football and the like (14). In patients with cervical spinal neuropraxia that leads to temporary tetraplegia, having Torg ratios 0,80 or less is considered as a significant spinal stenosis (15). Patients with longterm ankylosing spondylitis (AS) experience anatomical changes in their vertebras which lead to deformities, loss of ankylose and vertebral immobility, decrease in shockabsorbing capability and osteoporosis that stem from the natural course of the disease. Therefore, such patients are more prone to fractures and they have a high risk rate for cervical spinal cord injuries. Ankylosing spondylitis is a chronic inflammatory rheumatic disease and it is prevalent in $0,1 \%$ and $1,4 \%$ of general population. It is accompanied particularly by progressive ossification in axial skeleton. Generally, $80 \%$ of the patients experience the preliminary symptoms before age 30 . On the other hand, the symptoms may appear after age 45 in $5 \%$ of the patients (4). The disease has a strong association with HLA-B27 positivity. It often starts during mid-twenties from sacroiliac articulations and turns into square-like shapes and synostosis in vertebras. It leads to "bamboo cane" shape in long term. Osteoporosis accelerates in patients whose capability of mobility decrease. They become more vulnerable against traumas (16). Patients with ankylosing spondylitis may experience fractures in vertebra particularly in cervical region due to minor traumas. Fractures in cervical region occur often in C5-7 vertebras. These fractures may result in tetraplegia (16). In addition, posterior longitudinal ligament may experience ossification which may lead to cervical canal stenosis and therefore cervical myelopathy in patients with ankylosing spondylitis (12).

\section{MATERIAL and METHODS}

\section{Data and Measures}

The study was carried out with patients who were diagnosed and treated in the polyclinic of Department of Physical Medicine and Rehabilitation. The patients have had ankylosing spondylitis for at least 10 years. Lateral cervical radiographies of the patients were used in the study. Sagittal thickness of $\mathrm{C} 2-\mathrm{C} 7$ vertebral bodies and sagittal diameter of vertebral canal (the distance where all vertebral levels were the narrowest) were measured. Figure 1). Diameter of vertebral canal and vertebral body thickness were proportioned and Torg ratio was calculated.

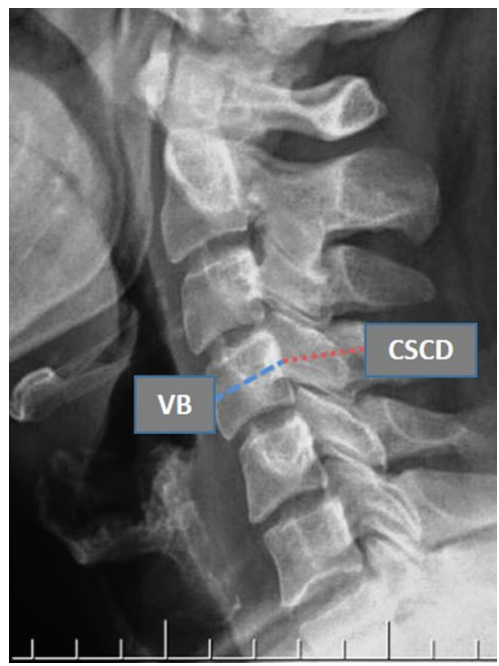

Figure 1. Measurment parameters

Table 1. Descriptive statistics of measures according to sex and age (40-50) group* $¥ ¥$

\begin{tabular}{|c|c|c|c|c|c|c|c|c|c|}
\hline \multicolumn{6}{|c|}{ WOMEN } & \multicolumn{4}{|c|}{ MEN } \\
\hline AGE & Parametres & Min & Max & Mean & SD & Min & Max & Mean & $\mathrm{SD}^{*}$ \\
\hline & C2 CSCD/VBD & 0.9307 & 1.2558 & 1.054844 & 0.1020381 & 0.6820 & 1.2388 & 0.983402 & 0.2000977 \\
\hline & C3 CSCD/VBD & 0.8449 & 1.3885 & 0.978527 & 0.1392835 & 0.6610 & 1.1224 & 0.958092 & 0.1407031 \\
\hline & C4 CSCD/VBD & 0.8000 & 1.3624 & 0.966811 & 0.1385368 & 0.6778 & 1.1000 & 0.963557 & 0.1217771 \\
\hline & C5 CSCD/VBD & 0.7749 & 1.0060 & 0.917479 & 0.0645226 & 0.7119 & 1.1479 & 0.950298 & 0.1396697 \\
\hline & C6 CSCD/VBD & 0.7411 & 1.0787 & 0.904038 & 0.0965392 & 0.7336 & 1.0785 & 0.937283 & 0.1108004 \\
\hline & C7 CSCD/VBD & 0.7895 & 1.1006 & 0.938055 & 0.0879392 & 0.7066 & 0.9946 & 0.862754 & 0,0862186 \\
\hline & C2-VBD & 1.6300 & 2.0700 & 1.847692 & 0.1307768 & 1.9300 & 2.4200 & 2.144444 & 0.1709613 \\
\hline $40-50$ & C3-VBD & 1.5700 & 2.0000 & 1.794615 & 0.1192767 & 1.8500 & 2.3600 & 2.032222 & 0.1509783 \\
\hline & C4-VBD & 1.4900 & 2.0500 & 1.764615 & 0.1385409 & 1.8000 & 2.900 & 1.998889 & 0.1910134 \\
\hline & C5-VBD & 1.6700 & 2.0800 & 1.816154 & 0.1144216 & 1.6900 & 2.3600 & 2.017778 & 0.2158575 \\
\hline & C6-VBD & 1.7200 & 2.0200 & 1.876923 & 0.1061747 & 1.8800 & 2.2900 & 2.040000 & 0.1364734 \\
\hline & C7-VBD & 1.6900 & 2.0500 & 1.883846 & 0.0960502 & 1.8400 & 2.4200 & 2.140000 & 0.1721918 \\
\hline & C2-CSCD & 1.6700 & 2.1600 & 1.940769 & 0.1330076 & 1.6300 & 2.4900 & 2.086667 & 0.3328663 \\
\hline & C3-CSCD & 1.800 & 2.1800 & 1.744615 & 0.1586724 & 1.5600 & 2.2000 & 1.934444 & 0.2337259 \\
\hline & C4-CSCD & 1.5200 & 2.0300 & 1.693077 & 0.1520627 & 1.200 & 2.0900 & 1.908889 & 0.1590947 \\
\hline & C5-CSCD & 1.4800 & 1.8500 & 1,656154 & 0.1092809 & 1.6800 & 2.1100 & 1.894444 & 0.1591470 \\
\hline & C6-CSCD & 1.4600 & 1.9800 & 1.688462 & 0.1506014 & 1.6800 & 2.0900 & 1.01111 & 0.1491178 \\
\hline & C7-CSCD & 1.5000 & 2.0000 & 1.784615 & 0.1525131 & 1.5900 & 1.9800 & 1.836667 & 0.1288410 \\
\hline
\end{tabular}

*:SD: Standard deviation, "*:Factorial analysis of variance model with two factor, $¥:$ Minimal values are represents with bold 
Table 2. Descriptive statistics of measures according to sex and age (50-60) group", $¥$

\begin{tabular}{|c|c|c|c|c|c|c|c|c|c|}
\hline \multicolumn{6}{|c|}{ WOMEN } & \multicolumn{4}{|c|}{ MEN } \\
\hline \multirow[t]{8}{*}{ AGE } & Parametres & Min & Max & Mean & SD & Min & Max & Mean & $S^{*}$ \\
\hline & C2 CSCD/VBD & 0.9559 & 1.5030 & 1.184482 & 0.1834136 & 1.0093 & 1.2921 & 1.094988 & 0.1138123 \\
\hline & C3 CSCD/VBD & 0.8333 & 1.2189 & 1.038551 & 0.1305573 & 0.9794 & 1.0142 & 0.991483 & 0.0138105 \\
\hline & C4 CSCD/VBD & 0.7946 & 1.2013 & 0.984803 & 0.1367956 & 0.8100 & 0.9944 & 0.904787 & 0.0892923 \\
\hline & C5 CSCD/VBD & 0.7437 & 1.2364 & 0.953242 & 0.1519995 & 0.7822 & 0.9602 & 0.897551 & 0.0766465 \\
\hline & C6 CSCD/VBD & 0.7455 & 1.2242 & 0.919895 & 0.1341177 & 0.7490 & 1.0215 & 0.889410 & 0.0967563 \\
\hline & C7 CSCD/VBD & 0.8000 & 1.1557 & 0.908778 & 0.0936915 & 0.7419 & 0.9773 & 0.873191 & 0.1012740 \\
\hline & C2-VBD & 1.5900 & 2.0500 & 1.822857 & 0.1416077 & 1.9300 & 2,1600 & 2.026000 & 0.0968504 \\
\hline \multirow[t]{11}{*}{$50-60$} & C3-VBD & 1.5600 & 2.1000 & 1.792143 & 0.1629619 & 1.8300 & 2.200 & 1.962000 & 0.1147606 \\
\hline & C4-VBD & 1,5500 & 2.2400 & 1.805714 & 0.1951612 & 1.8000 & 2.3200 & 2.038000 & 0.1895257 \\
\hline & C5-VBD & $1, .700$ & 2.800 & 1.829286 & 0.2184725 & 1.9400 & 2.3300 & 2.104000 & 0.1740115 \\
\hline & C6-VBD & 1.6500 & 2.2400 & 1.877143 & 0.1639619 & 1.8600 & 2.4600 & 2.150000 & 0.2882707 \\
\hline & C7-VBD & 1.6700 & 2.1000 & 1.918571 & 0.1493502 & 1.9200 & 2,4800 & 2.170000 & 0.2154066 \\
\hline & C2-CSCD & 1.7600 & 2.6600 & 2.144286 & 0.2660455 & 2.0600 & 2.6100 & 2.216000 & 0.2250111 \\
\hline & C3-CSCD & 1,5600 & 2.0600 & 1.845714 & 0.1441535 & 1.8200 & 2.1500 & 1.946000 & 0.1322120 \\
\hline & C4-CSCD & 1.5100 & 2.0600 & 1.758571 & 0.1424434 & 1.6200 & 2.0600 & 1.836000 & 0.1597811 \\
\hline & C5-CSCD & 1,4800 & 2.0400 & 1.717857 & 0.1422986 & 1.6600 & 2.900 & 1.886000 & 0.2008233 \\
\hline & C6-CSCD & 1.5200 & 2.0200 & 1.710714 & 0.1493300 & 1.7000 & 2.1900 & 1.896000 & 0.1811905 \\
\hline & C7-CSCD & 1.6000 & 1.800 & 1.734286 & 0.1211937 & 1.7500 & 2.1500 & 1.882000 & 0.1554670 \\
\hline
\end{tabular}

Radiographies of twenty-eight females and fourteen males were evaluated. Both female and male patient groups were divided into two according to ages which were $40-50$ and 50-60 respectively. In order to make a comparison with our data and data obtained from healthy individuals, averages from 90 people from literature were used. These people's ages were ranging from 30 to 33 . 45 of them were females whereas the rest 45 were males (8). Measurements on lateral cervical radiographies were made in digital environment using ClearCanvas Workstation packet software.

\section{Ethical consideration}

For the study permission received from the ethics committee Düzce University Medicine Faculty (11.10.2013/2013-456).

\section{RESULTS}

Table 1-2 shows vertebral thicknesses derived from lateral cervical radiographies from $40-50$ and $50-60$ age groups, vertebral canal diameters and descriptive statistical data regarding Torg ratio as well as minimum, maximum, average and standard deviation values.

Considering data, there was no difference in second cervical vertebra based on sex in terms of Torg ratio. However, 50-60 age groups had higher rates compared to 40-50 age group. Moreover, the difference between them was found statistically significant $(P=0.031)$. No statistically significant difference could be detected in terms of Torg ratio in C3-C6 vertebral levels based on age and sex. Even though Torg ratio levels were higher in females in C7 vertebral level, this difference was not statistically significant $(P=0.081)$. No statistically significant difference could be found between age groups in terms of VBD. When vertebra thicknesses were compared at all levels ( $\mathrm{C} 2-\mathrm{C} 7)$ based on sex, it was seen that males significantly have higher levels $(P<0.001)$. No significant difference was revealed in second cervical vertebra based on CSCD between sexes. When age groups were compared, it was seen that CSCD was larger in 50-60 age group $(p<0.05)$. As for the rest of the cervical vertebras, there was no difference in CSCD according to age groups. However, males had larger CSCD compared to females. This difference was statistically significant $(p<0.001)$. In all of the findings, neither the differences between sexes in terms of VBD, CSCD and Torg ratio nor the differences between age groups varied by one another. In other words, the interaction between age group and sex was not significant. The lowest Torg ratio for females within 40-50 age groups was $\mathrm{C} 6$ whereas it was $\mathrm{C} 7$ for age group 5060 . The lowest Torg ratio for males in both age groups was C7 (Table 3).

Table 3. Percentages regarding vertebra levels with the lowest Torg ratios

\begin{tabular}{lccc} 
Torg Ratio & \multicolumn{3}{c}{ Gender } \\
& $\mathbf{K}(\%)$ & $\mathbf{E}(\%)$ & Total \\
C2 & 0 & 7.1 & 2.4 \\
C3 & 7.4 & 7.1 & 7.3 \\
C4 & 11.1 & 14.3 & 12.2 \\
C5 & 11.1 & 7.1 & 9.8 \\
C6 & $33.3^{*}$ & 0 & 22 \\
C7 & 37 & $64^{*}$ & $46^{*}$
\end{tabular}

Pearson Chi- Square testi $\left({ }^{*} p<0,021\right)$ 
Considering percentages of levels with the narrowest CSCD, the highest levels for females in this category were in $\mathrm{C} 4$ and $\mathrm{C} 6$ whereas it was $\mathrm{C} 3$ and $\mathrm{C} 7$ in males. The difference between females and males was statistically significant $(P=0.021)$ (Table 4).

\begin{tabular}{|c|c|c|c|}
\hline \multirow[t]{2}{*}{$\begin{array}{l}\text { The narrowest } \\
\text { CSCD Levels }\end{array}$} & \multicolumn{2}{|c|}{ Gender } & \multirow[b]{2}{*}{ Tota } \\
\hline & K (\%) & $E(\%)$ & \\
\hline C3 & 7.4 & $28.6 *$ & 14.6 \\
\hline C4 & $33.3 *$ & 14.3 & 26.8 \\
\hline C5 & 11.1 & 7.1 & 9.8 \\
\hline C6 & 37.0 * & 7.1 & 26.8 \\
\hline C7 & 11.1 & $42.9 *$ & 22.0 \\
\hline
\end{tabular}

Pearson Chi- Square testi $\left({ }^{*} p<0,021\right)$

In the radiographies evaluated for this study, percentage of Torg ratio at a level of 0.80 or less in females was $25.90 \%$ whereas the percentage for males was $21.40 \%$. In some of the radiograms, more than one cervical vertebra levels had Torg ratios at a level of 0.80 or less. Table 5 shows the percentages of detected Torg ratio levels in each cervical vertebra level at a level of 0.80 or less.

\begin{tabular}{|c|c|c|c|c|c|c|}
\hline & $\begin{array}{l}\text { C2 } \\
\text { CSCD/ } \\
\text { VBD }\end{array}$ & $\begin{array}{l}\text { C3 } \\
\text { CSCD/ } \\
\text { VBD }\end{array}$ & $\begin{array}{l}\text { C4 } \\
\text { CSCD/ } \\
\text { VBD }\end{array}$ & $\begin{array}{l}\text { C5 } \\
\text { CSCD/ } \\
\text { VBD }\end{array}$ & $\begin{array}{l}\text { C6 } \\
\text { CSCD/ } \\
\text { VBD }\end{array}$ & $\begin{array}{l}\text { C7 } \\
\text { CSCD/ } \\
\text { VBD }\end{array}$ \\
\hline Women & 0 & 0 & $11.1 \%$ & $18.5 \%$ & $14.8 \%$ & $7.4 \%$ \\
\hline Men & $14.2 \%$ & $7.14 \%$ & $7.14 \%$ & $21.4 \%$ & $14.2 \%$ & $14.2 \%$ \\
\hline
\end{tabular}

\section{DISCUSSION}

The anterior-posterior diameter of cervical spinal canal is an important indicator to estimate the possible pressure on spinal cord by developmental narrowing (14). This distance can be estimated through lateral neck radiographies and sagittal computerized tomography midline incisions. Considering all cervical vertebras, the levels in which this canal is narrowest may vary depending on race. In a study carried out in China, it was revealed that both males and females have the narrowest CSCD in C4 vertebra level (16.2-15.7r respectively) (14). Similarly, in a study carried out in Japan, the narrowest CSCD level was found to be C4 and in another study it was reported to be $C 5(5,6,10,11)$. Studies on Caucasian race often indicated that the narrowest canal belongs to C4 vertebra level. However, there are also previous studies suggesting that the canal was the narrowest in C2, C6, C7 vertebra levels (1-3). The narrowest segments of CSCD in this study for females within 40-50 age group was found $C 5(16.5 \pm 0.10)$ and within 50-60 age group it was found C6. (17.1 \pm 0.14$)$ whereas it was $\mathrm{C} 7$ for males within $40-50$ age group (18.3 \pm 0.12 ) and $C 4$ for $50-60$ age group (18.3 \pm 0.15$)$. In another study conducted in Turkey, the narrowest CSCD was found in C4 for both sexes and the detection was $13.71 \pm 2.36-12.85 \pm 2.00$ for males and females respectively (8). The lowest VBD average in this study was found within 40-50 age group for both sexes in C4 vertebra (17.6 $\pm 0.13-19.9 \pm 0.19$; females and males respectively). The lowest value of the same distance for 50-60 age groups was found in C3 vertebra in both sexes (17.9 $\pm 0.16-19.6 \pm 0.11$; females and males respectively). A similar study was conducted in Turkey with an age average of 30 for males and 33 for females covering people without ankylosing spondylitis. Average VBD was the lowest in C2 vertebra for males $(17.71 \pm 2.74)$ and C4 for females (15.31 \pm 2.99$)$ (3). In another study conducted in China, VBD distance for both sexes was found the lowest in C5 vertebra (15.8-18.5; females and males respectively). In this study, Torg ratio was the lowest in C7 vertebra level for males $(0.86 \pm 0.08-0.87 \pm 0.10$, age groups respectively), while it was $\mathrm{C} 6$ for females within 40-50 age groups $(0.904 \pm 0.09)$ and $C 7$ for females within $50-60$ age groups $(0.908 \pm 0.09)$. In another study conducted in Turkey, Torg ratio was found the lowest in C4 vertebra level for both sexes while the average values were $0.73 \pm 0.18-0.79 \pm 0.15$ for males and females respectively (8). A similar study was conducted in China and the lowest Torg ratio values were found in C4 vertebra levels for both sexes (0.7-0.98; males and females respectively). Ankylosing spondylitis is a chronic inflammatory disease. Minor traumas may occur during the natural course of the disease. Such traumas may lead to spinal fractures and therefore they may result in spinal cord injuries, posterior longitudinal ligament ossification, spinal canal stenosis and myelopathy as an extension of stenosis. Moreover, it may lead to central cord contusion without trauma, atlantoaxial dislocation and basilar invagination based on spinal ankylosing (17). Early diagnosis in terms of complications and appropriate treatment may prevent unintended spinal cord lesions. Furthermore, it aids decreasing permanent neurological morbidity rate (17). Sagittal Spinal Cord Diameter is approximately $10 \mathrm{~mm}$ in cervical region. CSCD is $17-18 \mathrm{~mm}$ in normal individuals and if this distance falls below $12 \mathrm{~mm}$, it indicates a risk of myelopathy. The lowest CSCD distance detected in this study was found in females within $40-50$ age group as $14.6 \mathrm{~mm}$, and $14.8 \mathrm{~mm}$ for females within 50-60 age group.

\section{CONCLUSION}

Cervical myelopathy is a sneaky disease with symptoms such as frequent aches in upper extremity, paresthesia in hands, and difficulty in writing and disordered handwriting. Cervical radiographies constitute the first diagnosis method when myelopathy is considered for a patient. According to data obtained from cervical radiographies, patients with ankylosing spondylitis should be monitored more frequently against myelopathy if spinal canal diameter and Torg ratio are found close to limit values.

Competing interests: The authors declare that they have no competing interest.

Funding: There are no financial supports.

Ethical approval: This work has been approved by the Institutional Review Board. 


\section{REFERENCES}

1. Gupta SK, Roy RC, Srivastava A. Sagittal diameter of the cervical canal in normal Indian adults. Clin Radiol 1982;33(6): 681-5.

2. Burrows $\mathrm{EH}$. The sagittal diameter of the spinal canal in cervical spondylosis. Clin Radiol 1963;14:77-86.

3. Eismont FJ, Clifford S, Goldberg M, Green B. Cervical sagittal spinal canal size in spine injury. Spine 1984;9(7):663-6.

4. Feldtkeller E, Vosse D, Geusens $P$, van der Linden S. Prevalence and annual incidence of vertebral fractures in patients with ankylosing spondylitis. Rheumatol Int 2006;26(3):234-9.

5. Hashimoto I, Tak YK. The true sagittal diameter of the cervicaL spinal canal and its diagnostic significance in cervical myelopathy. Neurosurg 1977;47(6):912-6.

6. Hayashi H, Okada K, Hamada M, Tada K, Ueno R. Etiologic factors of myelopathy. A radiographic evaluation of the aging changes in the cervical spine. Clin Orthop Relat Res 1987;214:200-9.

7. Ko HY, Park JH, Shin YB, Baek SY. Gross quantitative measurements of spinal cord segments in human. Spinal Cord 2004;42(1):35-40.

8. Karabulut Ö, Karabulut Z. The variations of torg ratiowith genderin patients with neck pain. Dicle Medical Journal 2007;34:(4):272-4.

9. Lim JK, Wong HK. Variation of the cervical spinal Torg ratio with gender and ethnicity. Spine J 2004;(4):396-401.

10. Murone I. The importance of the sagittal diameters of the cervical spinal canal in relation to spondylosis and myelopathy. J Bone Joint Surg Br 1974;56(1):30-6.

11. Ogino $\mathrm{H}$, Tada $\mathrm{K}$, Okada $\mathrm{K}$, Yonenobu $\mathrm{K}$, Yamamoto $\mathrm{T}$, Ono $\mathrm{K}$, et al. Canal diameter, anteroposterior compression ratio, and spondylotic myelopathy of the cervical spine. Spine 1983;8(1):1-5.

12. Olivieri I, Fiandra E, Muscat C, Barozzi L, Tomassini C, Gerli R. Cervical myelopathy caused by ossification of the posterior longitudinal ligament in ankylosing spondylitis. Arthritis Rheum 1996;39(12):2074-7.

13. Sherman JL, Nassaux PY, Citrin CM. Measurements of the normal cervical spinal cord on MR imaging. AJNR Am J Neuroradiol 1990;11(2):369-72.

14. Torg JS, Naranja RJ Jr, Pavlov H, Galinat BJ, Warren R, Stine RA. The relationship of developmental narrowing of the cervical spinal canal to reversible and irreversible injury of the cervical spinal cord in football players. J Bone Joint Surg Am 1996;78(9):1308-14.

15. Torg JS, Pavlov H, Genuario SE, Sennett B, Wisneski RJ, Robie $\mathrm{BH}$, et al. Neurapraxia of the cervical spinal cord with transient quadriplegia. J Bone Joint Surg Am 1986;68(9):1354-70.

16. Tugcu I, Yılmaz B, Tezel K, Yazıcıoglu K, Mohur H. Latrogenic Cervical Fracture in a Case with Ankylosing Spondylitis and Rehabilitation Practices. Turk J Phys Med Rehab 2010;56:(2)88-90.

17. Weinstein PR, Karpman RR, Gall EP, Pitt M. Spinal cord injury, spinal fracture, and spinal stenosis in ankylosing spondylitis. J Neurosurg 1982;57(5):609-16. 